International Journal of Engineering \& Technology, $7(4.5)(2018) 736-741$
International Journal of Engineering \& Technology
SPC
Website: $\frac{w w w . s c i e n c e p u b c o . c o m / i n d e x . p h p / I J E T}{2}$
Research paper

\title{
Design of floatable monolithic breakwater structure to ensure tranquility in port and harbor basins
}

\author{
Anjali Sebastian ${ }^{1}$, Sruthy $\mathbf{S}^{2}$, Jayadeep Thuvassery ${ }^{3}$ \\ ${ }^{1}$ Department of Civil Engineering, Amrita School of Engineering, Coimbatore, Amrita Vishwa Vidyapeetham, Amrita University, India \\ ${ }^{2}$ Assistant Professor, Department of Civil Engineering, Amrita School of Engineering, Coimbatore, Amrita Vishwa Vidyapeetham, Amri- \\ ta University, India \\ ${ }^{3}$ Assistant Executive Engineer, Harbour Engineering Department, Beypore, India \\ *Corresponding author E-mail: anjalisebastian.gec@gmail.com
}

\begin{abstract}
The objective of this paper is to present the selection, the detailing and optimal design of a floatable monolithic breakwater structure at Ponnani harbour in Kerala, India. Ponnani fishery harbour is an estuarine harbour and the breakwaters here serve the main purpose of river training bunds. Studies on preliminary analysis of tranquility condition in front of the wharf structure at Ponnani fishery harbour was conducted jointly by the Investigation subdivision, Beypore and Centre for Water Resources Development and Management (CWRDM), Pune. It has been noticed that due to seasonal variation in the wave directions, wave heights inside the basin areas and near the water front structures of the harbour are not within the permissible limits. A floating breakwater structure (FBS) is suggested to change the direction of waves and surges with seasons.

The present proposal consists of construction of a floatable monolithic breakwater structure of length 70m. A pile restrained pontoon floating breakwater structure is adopted for Ponnani harbour. The ability of FBS to attenuate the incident wave is determined by calculating the transmission coefficient. Theoretical formulas are used to check the effectiveness of the suggested FBS. The FBS has been modelled, analysed and arrived at an optimal design using the ANSYS software.
\end{abstract}

Keywords: Floating Breakwater Structure (FBS); Pile Restrained Type; Significant Wave Height; Transmission Coefficient; ANSYS Software.

\section{Introduction}

A breakwater is a structure constructed for the purpose of forming an artificial harbour with a basin, to shield from the impact of waves and to give safe berthing to fishing vessels. There are many different types of breakwaters. Natural rock and concrete, or a combination of the two materials that form 95 percentage or more of all the breakwaters constructed. Among these floating breakwaters are more feasible in poor soil conditions, ice formation problem, not as obtrusive as fixed breakwaters and can be more aesthetically pleasing. The efficiency of floating breakwater structure can be analysed theoretically by the parameter called transmission co-efficient. Which is the ratio of transmitted wave height to the incident wave height. The dynamic wave pressure is the most important wave property, which governs the design of FBS. ANSYS Software enables easy analysis and arriving at optimal design.

\section{Problem definition}

During site inspections and field survey, it was found that there are many reasons for the anglers not using the wharf. This includes the presence of the fish auction and marketing business now concentrated away from the wharf, resistance to change from people inclined to use the old ways of doing things etc., But, there have been also complaints that the tranquility conditions in front of the wharf is not helpful for easy landing of the fish. Instead of depending on here-says and opinions to find a solution to theproblem, it was decided to collect preliminary data and assess the situation using technical methods.

\subsection{Tranquility measurements at wharf}

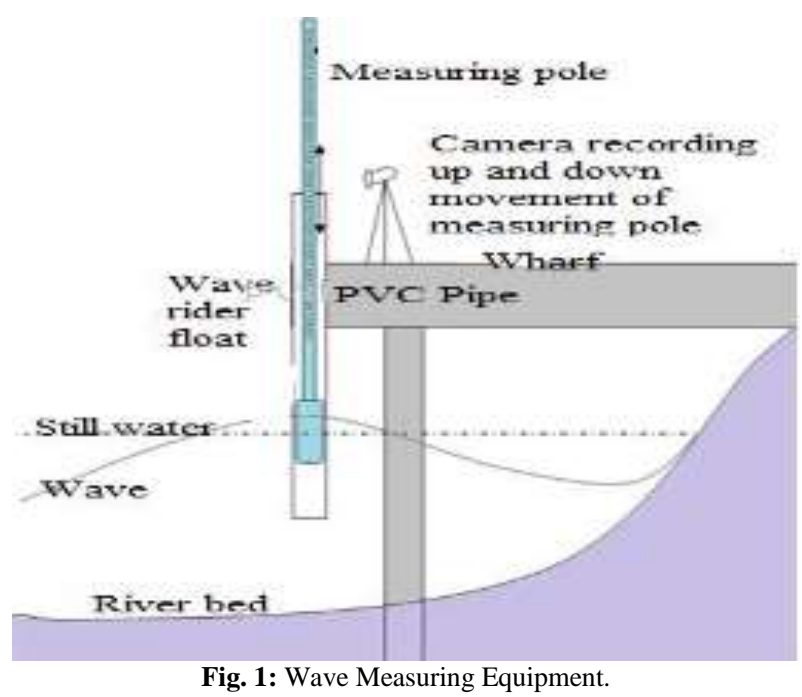

A heavy wave rider float with a lightweight aluminium pole attached to it was used to measure waves at Ponnani wharf. The pole has measurements marked on it and the float and pole is in- 
serted inside a $10 \mathrm{~cm}$ diameter PVC pipe. This pipe has its bottom open and holes on sides. This allows free movement of water inside. The wave rider float hence has a free up-down motion when waves cross the pipe.

Very small wind waves at the surface of water cause only slight undulations in the readings as the float is heavy. The measurements were recorded using video so that the reading at second's interval could be retrieved by playing the video in slow mode. The tide was flooding during the observations.

After eliminating the wind waves of shorter periods and tidal effects, the resulting wave pattern showed multiple crests and troughs close together, separated by about 40 to 46 seconds. The multiple crests and troughs were found to be resulting from the wave getting reflected along the reclamation bund underneath the wharf.

A visit was also made to the tip of the Southern Breakwater to observe the ocean wave conditions. Waves were observed to be breaking due to shallow depths at the outer sea near the head of the southern breakwater. Considerable deposition seems to have happened in front of the approach channel, towards the south in the sea.

This shallow area was seen to diffract the waves as they enter the channel. Waves were seen to be travelling through the channel to the harbour basin at an angle of $270 \mathrm{o}$ to $280 \mathrm{o}$.

\section{Literature review}

Kelly[9] observed the advantages and disadvantages of the use of inflatable breakwaters. This kind of breakwater absorbs wave energy by its mass and mooring system as compared to the rigid breakwater structure.

McCartney [1] studied on different types of floating breakwaters in existence today mainly the box, pontoon, mat, and tethered types of float. Pontoon types include several different models, such as the ladder, catamaran, sloping-float and frame types. Pontoon types are generally less expensive than box types and have similar advantages and disadvantages to the box type.

Jones, Richey and Nece [12] noticed that the mass of structure, radius of gyration and depth of submergence are important factors that affects the performance of pontoon type breakwater.

U.S Army Corps of Engineers methods of operational aspects[4] suggests that the generally accepted criterion for evaluating a breakwater performance is transmission co-efficient, $\mathrm{Ct}$; which is the ratio of transmitted wave height to incident wave height. As with all the breakwaters, design of a floating breakwater is always site specific.

J. S. Mani [13] in his literature indicated that the parameter "relative width," i.e., the ratio of the width of the floating breakwater (B) to wavelength (L) influences greatly on the wave transmission char-acteristics of the breakwater.

Macagno [10] investigated a theoretical formula for the evaluation of transmission coefficient for a fixed breakwater structure submerged to a draft $(\mathrm{t})$ and water depth (d).

Ruol et al [10] developed a formula for transmission coeffi-cient for floating structures which is a modification over the formula of Macagno.

$$
C_{q}=\beta(j) C_{t} \text { (Maeagno) }
$$

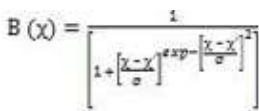

$\beta=$ modification factor based on curve fitting

$\chi^{\prime}=0.7919$, with $95 \%$ confidence interval $0.7801,0.8037, \sigma=$ 0.1922 , with $95 \%$ confidence interval $0.1741,0.2103$.

Cox et al. and Koutandos et al[10] concluded that for values of 0:6 $<\chi<3: 5$ the theory of Kriebel and Bollmann is good to apply. Kriebel and Bollmann[11] investigated the transmission co- efficient based on modified power transmission theory. It is a modified theory of Wiegal's transmission coefficient theory

$$
\begin{aligned}
& \frac{T_{p}}{T_{h}} \approx X=\frac{T_{p}}{2 \pi \times \sqrt[2]{\frac{g}{D+3 s a}}} \\
& C_{t \text { Kriebel }}=\frac{2 C_{t \text { weigal }}}{1+C_{t \text { weigal }}} \\
& C_{t \text { Bollmann }}=2\left[1+\frac{\sinh (2 k d)+2 k d}{2 k(d-t)+\sinh (2 k(d-t)}\right]
\end{aligned}
$$

KaiuweGraw, Hanikaldenhoff,Paul Mario Koola[3] studied that, pile restrained floating breakwater structure helps to improve the performance of FBS than mooring with cables/chains. This reduces the permitted roll motion and prevents sway motion.

Airy [8] developed most elementary wave theory which is used to find out fluid particle acceleration.

Bollmann[14] calculated the resulting pressure on the wall by the addition and subtraction of the dynamic pressure of the incoming, reflected and transmitted wave. He considered the less wave runup and reflection of the wall.

U.S Army corps of engineers[5] investigated the stiffness of mooring line connected to pile head.

\section{Proposed solution to the problem}

As a result of the above mentioned studies, the problem definition is arrived at as "Some amount of wave disturbances was present in front of the wharf when the observations were made. This can be a seasonal phenomenon, due to the insurgence of the ocean waves through the channel as result of the changes in their approach directions. This can also be aggravated due to the presence of shoals or sand bars in the outer sea immediately in front of the entrance of channel as is seen at present".

The engineering solutions for this can be either:

- Constructing a spur breakwater by extending the southern breakwater further towards east.

- Increasing length/overlap of breakwaters towards the sea, A long concrete box with water filling and pump out arrangement can be made on the shore, floats in position and sunk to provide shadow area from waves. The top of this can also be used as berthing wharf for idle vessels breakwater to bring the wharf area under shadow region

- Construction of new wharf elsewhere in an alignment and location suitable to the wave conditions inside the basin.

In the present case, having a floatable, concrete structure is decided as the best solution. This structure can be aligned to suit any directions of surges and waves. A detailed and proper mathematical modelling of breakwaters and the basin area will be required to arrive at the exact directions, alignment, orientation and layout of this floating structure. However, this is deemed outside the scope of the present work.

Presently, a rectangular pontoon floating breakwater structure is adopted for the site. The structure is connected to rows of pile on each side to support the structure. The system only provides upward and downward movement when waves hit the structure.

\section{Methodology}

In this work. an attempt is made to decrease the weight of the floating breakwater structure without exceeding allowable stress value. The quantity of the steel and concrete could be minimized to reduce the overall cost of the FBS construction at the all while ensuring the strength and life time of breakwater. Three dimensional model and static structural analysis of FBS models is performed in ANSYS workbench 14.5.

- Data such as wave characteristics, site details are collected from harbor engineering department at Ponnani. 
- Preliminary dimensions are chosen for the floating breakwater and the effectiveness of the selected geometry is evaluated by using the factor called transmission coefficient

- Required data has been collected from books and journals

- $\quad 3 \mathrm{D}$ modelling and static structural analysis of the floating breakwater is done using ANSYS workbench 14.5

- Meshing of model carried out by finite element method. The results show that the maximum Von-Mises stress is not within the limit.

- By static analysis with minimum reinforcements, floating breakwater is analysed and results are compared with plain concrete floating breakwater analysis.

\section{Design of floating breakwater structure}

\subsection{Preliminary` data analysis}

Investigation Subdivision Beypore requested to conduct measurements and a preliminary analysis of the tranquillity condition in front of the wharf at Ponnani Fishing Harbour, Malappuram District.

Table 1: Wave Heights

\begin{tabular}{ll}
\hline Seasonal Variation & Wave \\
\hline $\begin{array}{l}\text { May to September with wave heights } \\
\begin{array}{l}\text { During October to December sea is relatively } \\
\text { calm with wave heights }\end{array}\end{array}$ & $\begin{array}{l}\text { Heights } 3.0 \\
0.5 \text { to } 2.0\end{array}$ \\
$\begin{array}{l}\text { For the remaining period of the year the sea is } \\
\text { generally calm with light swells }\end{array}$ & $<1$ \\
\hline
\end{tabular}

\subsection{Selection of geometry of Floating breakwater}

Preliminary dimensions of floating breakwater is taken as $70 \mathrm{~m}$ length, $15 \mathrm{~m}$ width and $5 \mathrm{~m}$ depth. Structure is floated with freeboard $2 \mathrm{~m}$ and draft $3 \mathrm{~m}$. one wavelength of a wave is taken as length of breakwater. Width and draft has high influence in wave attenuation property of breakwater and these values are fixed based on transmission coefficient. Freeboard is fixed in order to limit the overtopping of wave. Pile restrained Pontoon type floating breakwater structure is adopted for Ponnani harbour. Pile restrained system only provides vertical translation of floating breakwater under regular and irregular wave conditions.

- $\quad$ Pile system provides more stability than using chains or cables.

- Rows of piles, which only cause heave motion and preventing sway motion.

\subsection{Performance of selected floating breakwater struc- ture}

Preliminary dimension is given to the structure and the performance of selected floating breakwater structure is evaluated theoretically by using the factor, transmission coefficient. Based on the transmission coefficient value the dimension of FBS is fixed for further design.

Table 2: Wave Parameters

Parameters
Significant wave height, $\mathrm{H}$
Peak time period, $\mathrm{T}$
Mean period, $\mathrm{T}=.9 * \mathrm{TP}$
Water depth ,d
Draft, $\mathrm{t}$
Freeboard

Wave length, $\mathrm{L}$

Wave number , $\mathrm{k}=2 \pi / \mathrm{L}$

Relative water depth, d / L

Draft /water depth $>=1 / 4$

(for roll mo-

tion $\Theta<10$ degree)

Wave steepness: $\mathrm{H} / \mathrm{L}$

Relative wave height: $\mathrm{H} / \mathrm{d}$

Relative submergence: $\mathrm{t} / \mathrm{L}$

Table 3: Calculation of Transmission Coefficient

Transmission Coefficient $(\mathrm{Ct})$ calculation

Dimensionless parameter,$\chi=\mathrm{Tp} / \mathrm{Th}$

$0.6<\chi<3.5$, the theory of Kriebel and Bollmann is

good applicable

Ct weigal 0.722

Ct kriebal 0.84

Ct bollman 0.68

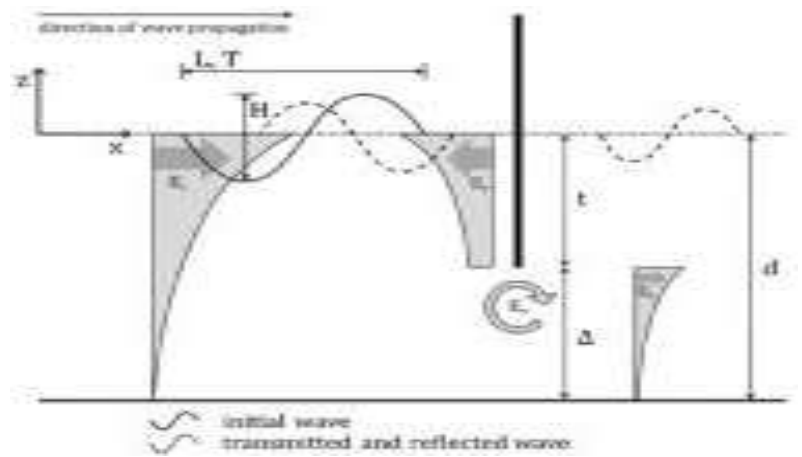

Fig. 2: Wave Propagation Diagram (Reference No 14)

Transmission co-efficient value calculated is 0.68 , which is adequate to attenuate the wave acting on the structure. Therefore, the dimension of FBS is fixed as $70 * 15 * 5 \mathrm{~m}$.

\subsection{Buoyancy and weight of structure calculation}

Floating constraint equation,

$-e_{m} v_{m} g+e_{e} v_{t} g<=0$

$\mathrm{em}=$ density of concrete

$\mathrm{vm}=$ volume of concrete

ee $=$ density of sea water

$\mathrm{vt}=$ volume of submerged part of breakwater $\mathrm{g}=$ gravitational constant $=9.81 \mathrm{~m} / \mathrm{s} 2$

Solving equation gets the thickness required to float the hollow rectangular structure.

Thickness $=300 \mathrm{~mm}$.

\subsection{Dead load}

Table 4: Dead Load Calculation

\begin{tabular}{lll}
\hline Parameters & Values & Units \\
\hline Dimensions of structure, $1^{*} \mathrm{~b} * \mathrm{~h}$ & $70 * 15 * 5$ & $\mathrm{~m}$ \\
Thickness of breakwater, $\mathrm{t}$ & 0.30 & $\mathrm{~m}$ \\
Density of concrete & 25.00 & $\mathrm{KN} / \mathrm{m}^{\wedge} 3$ \\
Dead load & 20370.00 & $\mathrm{KN}$ \\
\hline
\end{tabular}




\subsection{Impact load}

The magnitude of impact loading due to ship vessels collision with structure should be included in design loads. The maximum load can impact is its self-weight.

Impact load $=291.00 \mathrm{KN} / \mathrm{m}$

\subsection{Hydraulic loads}

\subsubsection{Fluid particle acceleration}

Table 5: Acceleration of Fluid Particle in X and Z Direction

\begin{tabular}{|c|c|c|}
\hline Acceleration (ax) & & Accelera- \\
\hline in $\mathrm{m} / \mathrm{s}^{2}$ & & tion $(\mathrm{az})$ in $\mathrm{m} / \mathrm{s}^{2}$ \\
\hline 0 & & -0.7326 \\
\hline-0.775536334 & & -0.592822983 \\
\hline-1.255134488 & & -0.226829673 \\
\hline-1.255783817 & & 0.225719944 \\
\hline-0.777236542 & & 0.592136717 \\
\hline-0.002102302 & & 0.732599071 \\
\hline 0.773834159 & & 0.593507745 \\
\hline 1.254481975 & & 0.227938827 \\
\hline 1.25642996 & & -0.224609642 \\
\hline 0.778934778 & & -0.591448949 \\
\hline 0.004204598 & & -0.732596283 \\
\hline-0.772130021 & & -0.594191002 \\
\hline-1.253826281 & & -0.229047402 \\
\hline-1.257072916 & & 0.223498771 \\
\hline-0.780631039 & & 0.590759681 \\
\hline-0.006306884 & & 0.732591638 \\
\hline 0.770423925 & & 0.594872751 \\
\hline $\begin{array}{l}\text { eleration (ax) } \\
\mathrm{a} / \mathrm{s}^{2}\end{array}$ & $\begin{array}{l}\text { Accelera- } \\
\text { tion }(a z) \text { in } \mathrm{m} / \mathrm{s}^{2}\end{array}$ & \\
\hline 3167406 & 0.230155397 & \\
\hline 7712684 & -0.222387332 & \\
\hline 2325319 & -0.590068915 & \\
\hline 8409154 & -0.732585134 & \\
\hline
\end{tabular}

\subsubsection{Dynamic wave pressure}

Dynamic wave pressure is calculated based on the Bollmann modified approach on linear wave theory. He has taken pressures due to diffraction and transmission of waves into account. Moreover, he considered the phase shift of $90^{\circ}$ between the front and rear of the baffle. The formula depends on the wave height $\mathrm{H}$, wave length $\mathrm{L}$, depth $\mathrm{d}$ and penetration depth $\mathrm{t}$ of the wall.

Table 6: Wave Load Calculation

\begin{tabular}{lll}
\hline \multicolumn{3}{c}{ Table 6: Wave Load Calculation } \\
\hline Parameters & Values & Units \\
\hline Dimensions of structure, $1 * \mathrm{~b} * \mathrm{~h}$ & $70 * 15 * 5$ & $\mathrm{~m}$ \\
Water depth, d & 7 & $\mathrm{~m}$ \\
Draft, t & 3 & $\mathrm{~m}$ \\
Sea water density & 1025 & $\mathrm{~kg} / \mathrm{m}^{2}$ \\
Wave length ,L & 70.25 & $\mathrm{~m}$ \\
Wave height, H & 3 & $\mathrm{~m}$ \\
Wave number ,K & 0.09 & $\mathrm{~m}$ \\
Transmission coefficient, $\mathrm{Ct}$ & 0.68 & \\
Dynamic wave pressure & 46975.51 & $\mathrm{Kg} / \mathrm{m}^{2}$ \\
\hline
\end{tabular}

\subsection{Mooring line stiffness}

The mooring line connected to pile head will have sufficient stiffness to carry the loads which is transferred from the structure. As per U.S Army corps of engineers, three different spring coefficients were considered.

$\mathrm{K} / \rho \mathrm{gL}=0.01$ for weak spring

$\mathrm{K} / \rho \mathrm{gL}=1$ for medium spring

$\mathrm{K} / \rho \mathrm{gL}=100$ for strong spring

Taking strong spring $\mathrm{k} / \rho \mathrm{gL}=100$
Stiffness $\mathrm{k}=\rho \mathrm{gL} * 100 \quad \mathrm{k}=7.064 * 10^{9} \mathrm{~N} / \mathrm{m}$

\section{Analysis of floating breakwater structure}

\subsection{Modelling}

Modelling and FEA analysis of structure is done using ANSYS software.

In order to validate the model, the practical condition is given in transient structural resulting fluid structural interaction. Fluid domain is created in geometry and given the sea water properties, the rows of piles on each side is connected to FBS by using springs having stiffness. The wave loading is given by acceleration of fluid particle calculated as per linear wave theory. The force reaction for completely fixed structure with manual calculation of dynamic pressure due to fluid is compared. Both method are approximately same, thereby the structure is ready to validate.

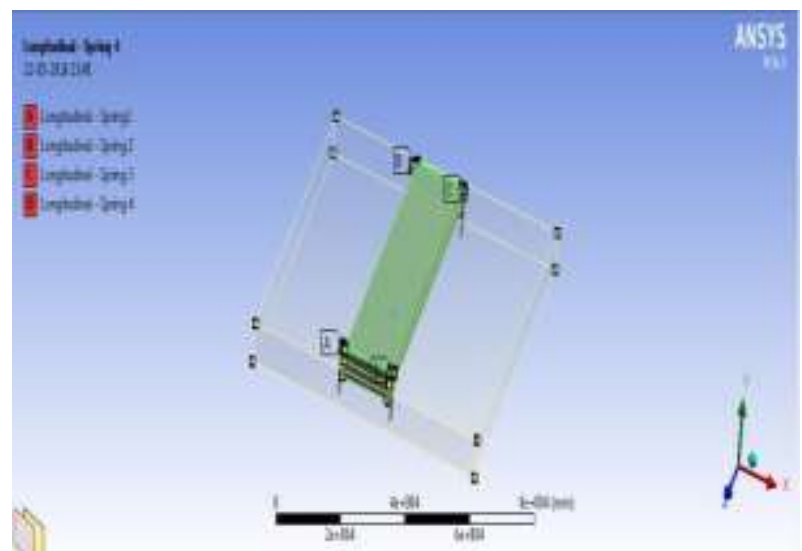

Fig. 3: Geometry of Pile Restrained FBS.

Table 7: Material Properties

\begin{tabular}{llll}
\hline Materials & Yield & Density & Modulus Of \\
\hline & Strength, & $\left(\mathrm{Kg} / \mathrm{m}^{\wedge} 2\right)$ & Elasticity, \\
& Mpa & & Mpa \\
Concrete & 35 & 2400 & 29580 \\
Steel & 415 & 7850 & 200000 \\
Water & & 1025 & 2200 \\
\hline
\end{tabular}

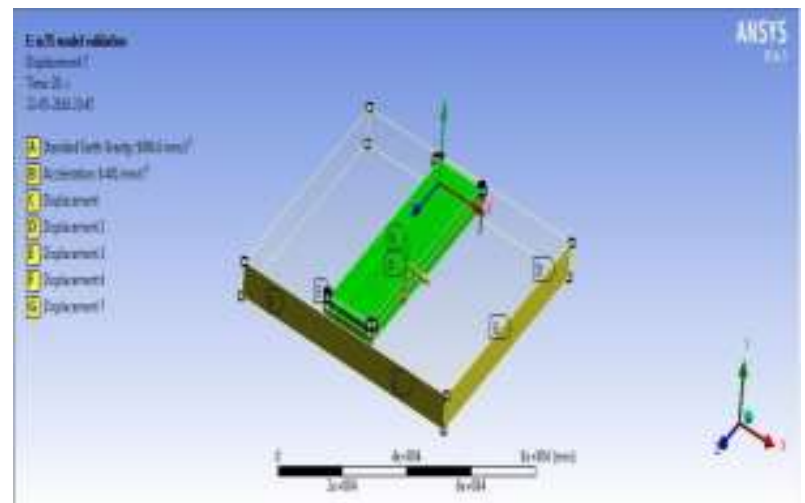

Fig. 4: Boundary Condition and Loading.

Table 8: Force calculation

\begin{tabular}{ll}
\hline Dynamic wave force (ANSYS ) & $458013100 \mathrm{~N}$ \\
\hline Dynamic wave force (linear wave & 471045727.8 \\
theory) & $\mathrm{N}$ \\
\hline
\end{tabular}

\subsection{Analysis of FBS using ANSYS software}

\subsubsection{Plain Concrete breakwate}

Materials such as concrete, steel and water is used for the analysis. After validating the model; the dynamic pressure, impact load and self-weight is given to the structure as compressive loads and 
boundary condition are given as fixity at the opposite side to get worst loading condition.

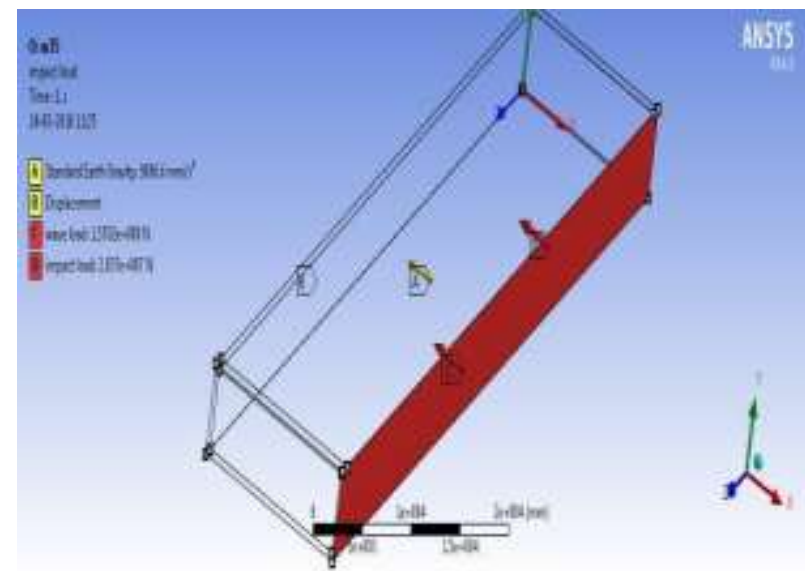

Fig. 5: Loading and Boundary Condition.

\subsubsection{Reinforced concrete breakwater}

As per IS 3370-part 2, the minimum reinforcement to reduce cracking due to temperature and shrinkage is calculated. Using IS 456-2000, the minimum shear reinforcement, spacing of bars, diameter of bars, cover to reinforcement are found out.

\begin{tabular}{|c|c|}
\hline Design parameters & $\begin{array}{l}\text { Val- } \\
\text { ues }\end{array}$ \\
\hline compressive strength of concrete & $35 \mathrm{Mpa}$ \\
\hline yield strength of steel & $415 \mathrm{Mpa}$ \\
\hline Thickness of structure & $300 \mathrm{~mm}$ \\
\hline $\begin{array}{l}\text { cover for reinforcement, severe con- } \\
\text { dition }\end{array}$ & $40 \mathrm{~mm}$ \\
\hline surface zone reinforcement & $\begin{array}{l}20 \mathrm{~mm} \varphi, 450 \\
\mathrm{~mm} \mathrm{c} / \mathrm{c} \mathrm{spac}- \\
\text { ing }\end{array}$ \\
\hline Bottom zone reinforcement & $\begin{array}{l}12 \mathrm{~mm} \\
\varphi, 215 \mathrm{~mm} \mathrm{c} / \mathrm{c} \\
\text { spacing }\end{array}$ \\
\hline shear reinforcement & $\begin{array}{l}16 \mathrm{~mm} \varphi, 180 \\
\mathrm{~mm} \mathrm{c} / \mathrm{c} \text { spac- } \\
\text { ing }\end{array}$ \\
\hline
\end{tabular}

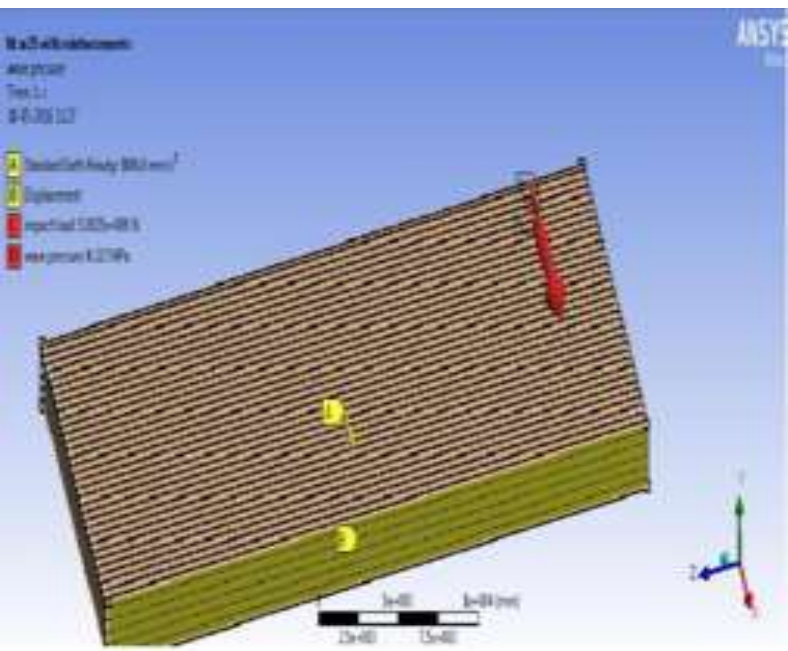

Fig. 6: Loading and Boundary Condition.

\subsection{Results and discussion}

\subsubsection{Plain Concrete breakwater}

The figures below show the stress pattern and total deformation occurring in the plain concrete structure. The von-Mises stress is greater than the strength of concrete and resulting in the failure of the structure.

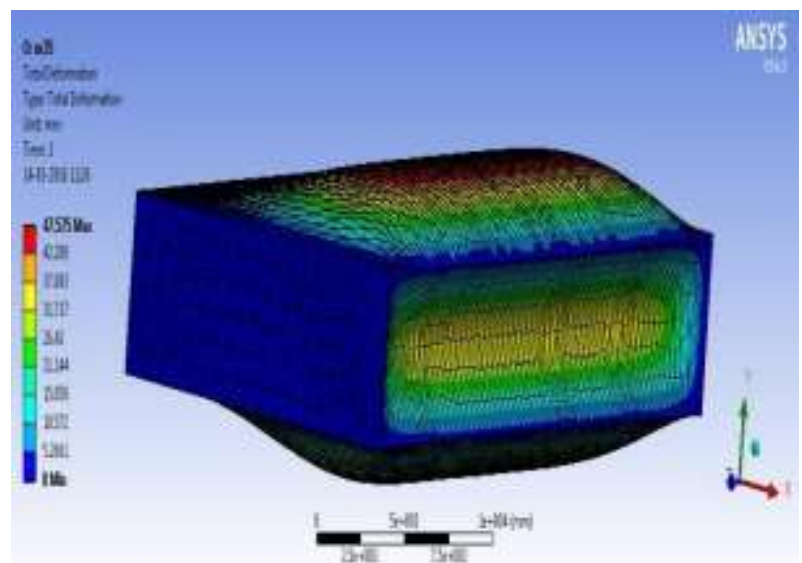

Fig. 7: Total Deformation Diagram.

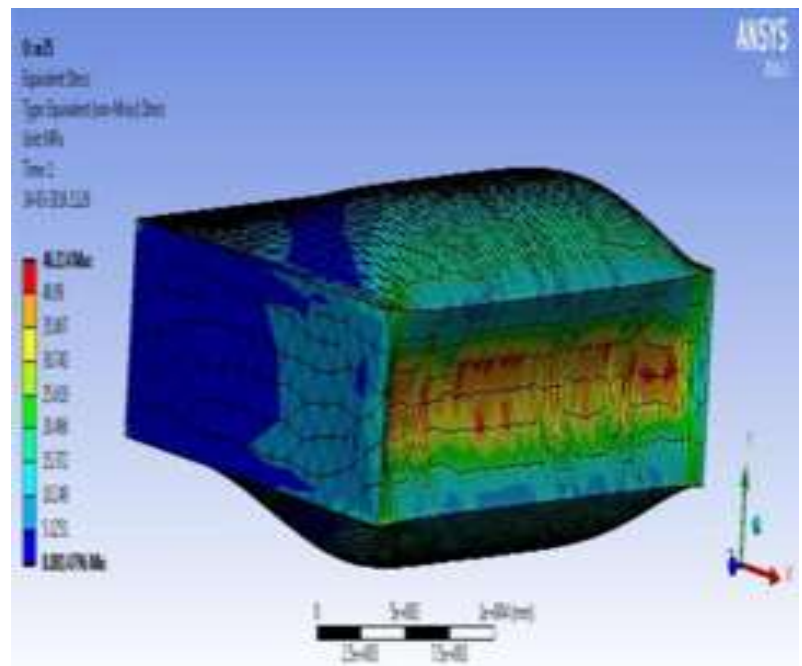

Fig. 8: Equivalent Stress Diagram.

Table 10: Analysis Results

\begin{tabular}{|c|c|}
\hline Parameters: & Values \\
\hline Strength of concrete & $35 \mathrm{Mpa}$ \\
\hline Equivalent Stress- Von Mises & 46.114 Мра \\
\hline Total Deformation & $47.575 \mathrm{~mm}$ \\
\hline Shear Stress & $7.0547 \mathrm{Mpa}$ \\
\hline
\end{tabular}

\subsubsection{Reinforced Concrete breakwater}

The structure is analysed with minimum reinforcements and stresses are getting within the acceptable limits.

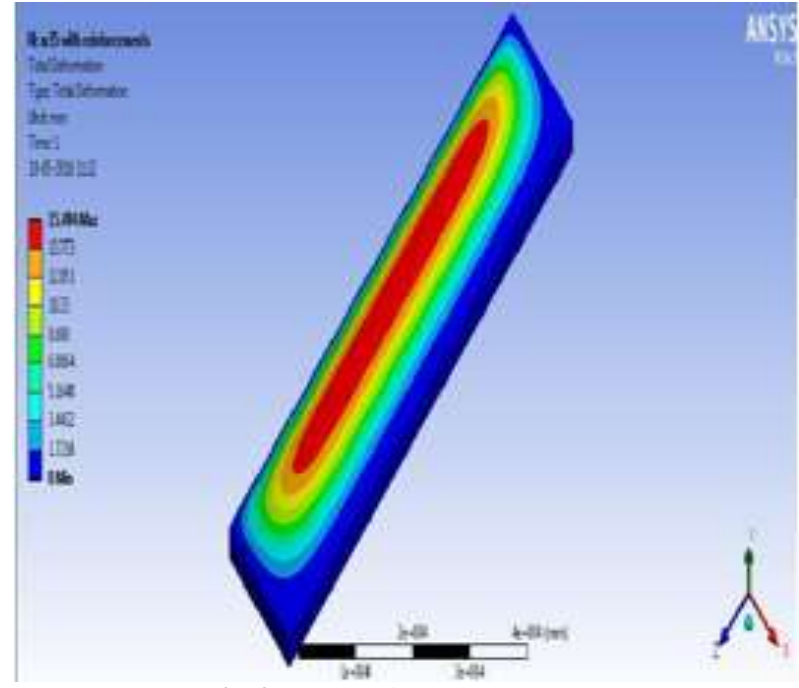

Fig. 9: Total Deformation Diagram. 
Table 11: Analysis Results

\begin{tabular}{ll}
\hline Parameters & Values \\
\hline Strength of concrete & $35 \mathrm{Mpa}$ \\
Equivalent Stress- Von Mises & $22.283 \mathrm{Mpa}$ \\
Total Deformation & $15.494 \mathrm{~mm}$ \\
\hline
\end{tabular}

\section{Summary and conclusion}

Preliminary data analysis collected the wave characteristics and site details and is completed. Wave heights inside the basin can be limited either by increasing the length of existing breakwater or by constructing a new breakwater that have a finite length. It has been analysed that constructing a monolithic rectangular floating breakwater can bring a calm area within the harbour basin. The performance of the selected breakwater structure is evaluated theoretically using factor called transmission coefficient. Analysis of breakwater structure with plain and reinforced concrete is done using ANSYS WORKBENCH 14.5.

The transient and static structural analysis on the floating breakwater was carried out. From the above results, it has been evaluated that the maximum shear stress and equivalent stress generated in the structure is under acceptable limit when reinforcements are used. Thus we conclude that the floating breakwater structure is safe under the action of various loads and support conditions applicable to ponnani harbor.

\section{Acknowledgement}

I would like to thank Amrita University for assistance during the course of this research and Mr.Jayadeep Thuvasseri (Assistant Executive Engineer, beypore) for comments that greatly improved the manuscript.

\section{References}

[1] Bruce L.Mccartney (1985), "Floating Breakwater Design

[2] Journel Of Waterways,Port,Coastal And Ocean Engineering, 111(2).

[3] A.N.Williams, P.T.Geiger, And W.G.Mc Dougal (1991), "Flexible Floating Breakwater", Journal of Waterways, Port, Coastal and Ocean Engineering, 117(5).

[4] Kai Uwe Graw, Hans Kaldenhoff, Paul Mario Koola (1999).

[5] "Behaviour Of Floating Breakwater Under Wave Action", Ph.D Thesis, Suez Canal University.

[6] Arie Cornelis Biesheuvel (2013), "Effectiveness Of Floating Breakwaters", M.Sc.Thesis, Delft University Of Technology.

[7] Army Corps Of Engineers (1984), "Shore Protection Manu-al”, Vol I.

[8] Army Corps Of Engineers (1984), "Shore Protection Manual”, Vol II.Army Corps Of Engineers (1984), "Shore Protection Manu-al”, Vol III.Coastal Engineering Manual (2002), Water Wave Mechan-ics,Part III

[9] Michael Isaacson and John Baldwin (1998), "WavePropaga-tion Past A Pile-Restrained Floating Break water", International Journal of Offshore and Polar Engineering, 8(4).

[10] 10.Zhi-Jie Chen, Yong-Xue Wang, Hua-Yang Dong, Bin-Xin Zheng (2012), "Time-Domain Hydro dynamic Analysis Of Pontoon-Plate Floating Breakwater", Water Science \& Engi-neering, PP 291-303.

[11] 11.Piero Ruol, Luca Martinelli and Polo ezzutto (2013), "Formu-la to Predict Transmission for pi-Type Floating Breakwaters", Journal of Waterway, Port, Coastal, And Ocean Engineering, 139(1).

[12] .J. S. Mani (1991), "Design of Y-Frame Floating Breakwater", Journal of Waterway, Port, Coastal, And Ocean Engineering, 117(2).

[13] Zidan,A.R, Rageh, Sarhan, And El-Sharabasy(2012), "Wave Interaction With Single And Twin Pontoons",Sixteenth In-ternational Water Technology Conference, IWTC 16.

[14] Bollmann (1996), "Wave interactions with vertical wave barriers", no.237, United States Naval Academy, Annapolis, US-NA Trident Scholar report.

[15] Huan-Yu Wang and Zhao-Chen Sun (2010), "Experimental Study on the Influence of Geometrical Configuration of Porous
Floating Breakwater on Performance", Journal of Marine Science and Technology, 18(4), PP: 574-579.

[16] By Lindell, Z.Hales (1981), "Floating Breakwater: State Of Art and Literature Review", U.S Army Corps of Coastal Engineering Research Center, Technical Report No 81. 17.

[17] T.Kowalski (1974), "Floating Breakwater Conference Papers".

[18] .Dr. Oluleke Oluwole, Dr.J.Odunfa, Olumide, P. Aboluwade (2015), "Investigating The Effect Of Ocean Waves On Gravi-ty Based Offshore Platform Using Finite Element Analysis Software ANSYS", International Journal Of Scientific \& Engineering Research, 6(8).

[19] Ketan Gajanan Nalawade, Ashish Sabu, Baskar (2014), "Dynamic and Static Structural Analysis of Ladder Frame", International Journal of Engineering Trends and Technology 11(2).

[20] Allsop, N.W.H.; Vicinanza, D.; Mckenna (1996), "Wave Forces On Vertical and Composite Breakwaters", Strategic Re-search Report. Hydraulic Research Wallingford, pp.94. 